\title{
Economic development and labor resources: age aspect
}

\author{
Tat'ayna Gorokhova ${ }^{1}$, Ludmila Pushkareva ${ }^{2}$, Mikhail Sredin ${ }^{3}$, and Mikhail Pushkarev ${ }^{4, *}$ \\ ${ }^{1}$ The National Open Institute in St. Petersburg, 197183, 6 Sestroretskaya str., St. Petersburg, Russia \\ ${ }^{2}$ North-West Institute of Management, branch of RANEPA, 199178, Sredny prospect VO, 57/43, St. \\ Petersburg, Russia \\ ${ }^{3}$ JSC "PMP", 1990046, 6A Birzhevoy pereulok, St. Petersburg, Russia \\ ${ }^{4}$ Saint-Petersburg State Institute of Technology, 190013, 26 Moskovsky prospect, St. Petersburg, \\ Russia
}

\begin{abstract}
Current demographic composition of labor resources in Russia, as well as increase of retirement age, legislatively set by government, encourage investigation of staff potential usage in regard of population age characteristics and identification of rational ways of employment for specialists in social production. Contemporary scientific editions devoted to sociology and economy are discussing actively problems of retirement age increasing and ways of involvement of elderly people into social life not only in metropolises, but also, in peripheral parts of the country. In the article, analysis of results of sociological survey, devoted to communicative skills of elderly, is made. Survey of "working» and "nonworking" retirees, concerned their live values, life guidance and communicative skill components. Taking into consideration two social groups, "working" and "non-working" old people, aims sociological elaborations on both directions.
\end{abstract}

\section{Introduction}

The increase in the proportion of elderly people in the total population of Russia while reducing the number of people of working age causes serious changes in the social policy of the state [1]. The increase in the retirement age in Russia for women from 55 to 63 years, and for men from 60 to 65 caused positive and negative responses from different social groups of the country's population [2].

The authors of this article to conduct a sociological analysis of different groups of pensioners prompted research Saratov State Medical University (SSMU) them. Razumovsky. At the Department of Philosophy, Humanities and Psychology of the named higher educational institution, a survey of young people of student age was conducted on the advisability of involving pensioners in the production process and the problems of older people. As a result of research at SSMU, it was found that $68 \%$ of young people consider people aged 55-60 to be "elderly people" in Russia. Although according to the classification of the World Health Organization, older people are people who have reached

\footnotetext{
*Corresponding author: malexpush@bk.ru
} 
75 years of age or more. Despite the fact that most retirees have an urgent need to earn money, only $58 \%$ of the young people surveyed believe that older people should be involved in performing production duties, and $42 \%$ of young people think that this is not necessary.

The main problem of pensioners is a worrying financial situation, i.e. As a result of the survey, it was found that older people do not have a monthly pension due to rising prices for food and medicine. Another significant problem for older people is loneliness. Given the fact that the average statistical life expectancy of men is lower than that of women, mainly women belong to the group of lonely elderly people. The employment of this contingent of the elderly is fraught with difficulties, because most employers believe that activity decreases with age. In addition, older people do not know information technology and communications and are difficult to learn, i.e. "Not so sharpened." This position indicates discrimination of older workers [3]. In the wake of nihilism, experienced specialists are pushed out of the production sphere, i.e. a specialist who has reached 45-50 years old is on the verge of dismissal. However, to strengthen the Russian economy, the need for experienced specialists is great, and the training of specialized personnel does not make up for this need. It should be noted that in the educational process and in production, a group of older specialists - mentors - completely disappeared.

The purpose of this study is to establish the feasibility of involving retirement age professionals in social production. In terms of personal initiative, the authors of this article conducted a sociological survey and analyzed its results in 2 groups of elderly people with a total of 40 people: "working pensioners" and "non-working pensioners." In the context of the goal, the level of income and material well-being, subjective characteristics of life orientations, the formation of communicative competencies. In order to obtain reliable conclusions in the process of the sociological research, the following methods were used: methods of conducting a sociological survey, informal psychodiagnostic conversation, the author's questionnaire "Subjective well-being of life", an observation card "Features of communicative competence", a test of "meaning-based life orientations".

\section{Methods and results}

During the analysis of the characteristics of the significance of values and well-being of older people in both groups by means of a survey, various criteria were identified that determine the levels of significance of life values. The analysis of the survey results is presented in table 1 .

Table 1. Analysis of the results of a survey of the importance of the life values of working and nonworking older people and the distribution of answers by rank

\begin{tabular}{|c|c|c|c|c|c|c|c|c|c|}
\hline Rank & 1 & 2 & 3 & 4 & 5 & 6 & 7 & 8 & 9 \\
\hline $\begin{array}{c}\text { 1st group: } \\
\text { employed elder } \\
\text { people }\end{array}$ & $\mathrm{Fa}$ & $\mathrm{He}$ & $\mathrm{Fr}$ & $\mathrm{MW}$ & $\mathrm{Na}$ & $\mathrm{Re}$ & $\mathrm{DR}$ & $\mathrm{Pl}$ & $\mathrm{SP}$ \\
\hline $\begin{array}{c}\text { 2nd group: } \\
\text { unemployed elder } \\
\text { people }\end{array}$ & $\mathrm{Fa}$ & $\mathrm{Fr}$ & $\mathrm{He}$ & $\mathrm{MW}$ & $\mathrm{Pl}$ & $\mathrm{Re}$ & $\mathrm{DR}$ & $\mathrm{Na}$ & $\mathrm{SP}$ \\
\hline
\end{tabular}

In the table. criteria (ranks) of the survey are presented in the form of symbols:

- Fr - reliable and loyal friends;

- Pl - life for pleasure;

- He - maintaining and improving health;

- Fa is a friendly family;

- MW - material well-being; 
- DR - self-development and self-realization;

- $\mathrm{Na}$ - love of nature;

- Re - love and interpersonal relationships;

- SP - a high position in society.

Comparing the answers of the respondents in both groups, the similarity of answers was revealed regarding the most valuable life criteria, of which they were assigned to the 1 st rank - "friendly family"; to the 4th rank - "material well-being", to the 6th rank - "love and interpersonal relationships", to the 7th rank - "self-development and self-realization", to the 9th rank - "high position in society". It should be noted that in the ranking system, working older people called the most valuable ranks - "life for pleasure" (8th rank), and among nonworking pensioners this position was only in 5th place. Such differences in judgments in people of retirement age are confirmed by statistical data and literature [4,5].

The issues of material well-being of working and non-working pensioners were studied in more detail, which allowed us to come to the corresponding conclusions. With a general shortage of monthly pension provision due to rising prices for food and medicine, payment of utilities, price lists for treatment, tariffs for travel expenses, the attitude to the growth of these expenses in different groups of pensioners studied is subjective [6]. Subjective material well-being is experienced by representatives from the group of working pensioners. Elderly people from this group who have additional labor income, show an active life position, are confident in themselves, successfully interact with others and experience positive emotions. In the group of non-working pensioners, a low level of pension provision causes emotional discomfort and dissatisfaction with the length of time spent in retirement.

To clarify the future intentions of older people in the analyzed groups of working and non-working pensioners, testing was conducted to identify the structure of "life meaning orientations" according to the criteria: purpose of life (PL); life process (LPr); result of life (LR). The test result is shown in Fig.1.

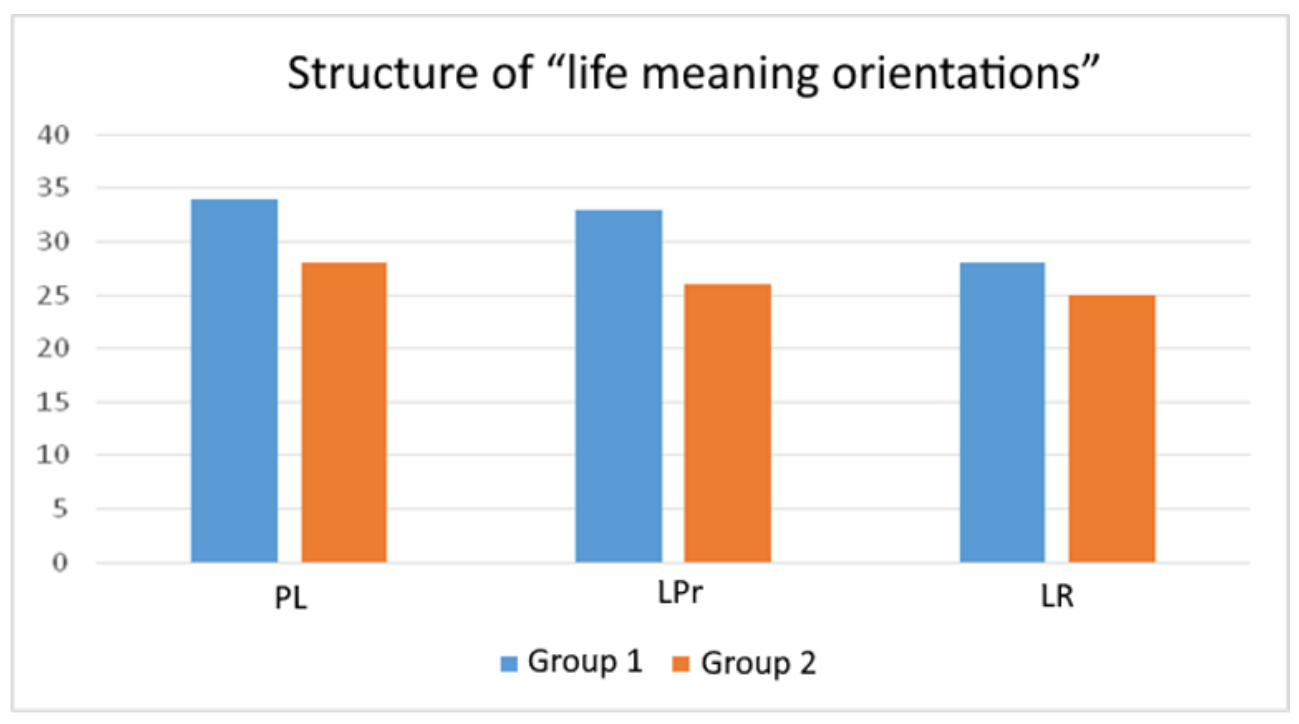

Fig. 1 The structure of "life meaning orientations" of older people

The ratio of group indicators in Fig. 1 shows that the group of working older people has higher rates that characterize the "meaning of life orientation." Even if all representatives of elderly groups are not satisfied with material support, working older people are more likely to experience positive emotions. Representatives of this group make plans for the future 
and develop ways to achieve them and implement them in a concrete way. Disabled elderly people are not inclined to make long-term plans due to the lack of material opportunities, and from real life they experience dissatisfaction and fatigue.

To answer the question of the appropriateness of involving older people in the sphere of social production, sociological observations were made, which were reflected in the study of the components of communicative competence and the construction of the corresponding schedule in Fig. 2

As criteria for sociological observations adopted: politeness in communication, tact (K1); correct speech (K2); adherence to ethics of communication (K3); sociability (K4); goodwill (K5); listening skills (K6); adequacy in the manifestation of verbal communication skills (K7); susceptibility to the style of communication of others (K8); eye contact support (K9); interest in other people's opinions (K10); the ability to engage in creative work, actively interacting with other participants in the process (K11); adequate analysis of external signals: facial expressions, intonations, body movements, etc. (K12); ability to extinguish conflicts (K13); ability to take into account the interests of another person (K14); possession of communicative tactics (K15); manifestation of business communication skills (K16).

\section{Components of the communicative competence}

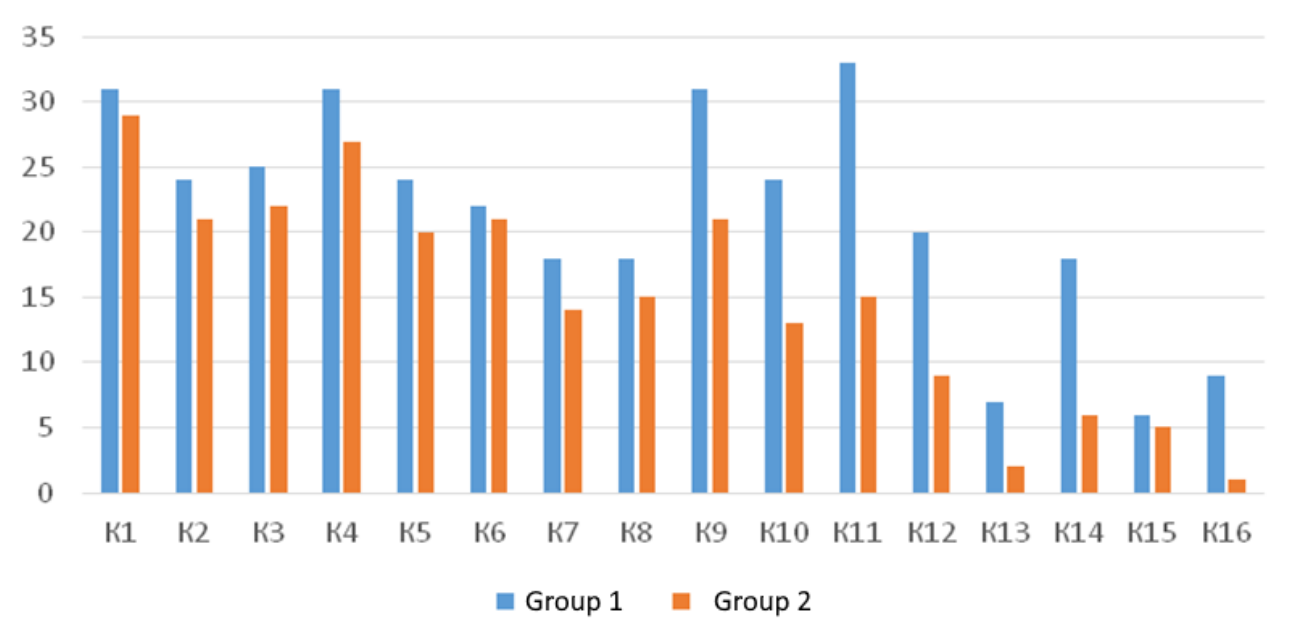

Fig. 2. Components of the communicative competence of older people

A common characteristic of the interviewed groups of working and non-working pensioners was a fairly high level of communicative competence, in particular in the field of sociability, politeness, knowledge of ethical communication standards, active listening skills, and susceptibility to the style of friendly communication. However, components in both groups of elderly people are not formed, such as "mastery of communicative tactics". In addition, the groups of working pensioners surveyed show a desire to actively participate in the creative process and a desire to maintain eye contact with an interlocutor of any age with the ability to take into account the opinions and interests of the younger generation.

\section{Conclusion}

In conclusion, when comparing all the results carried out in different aspects of the sociological analysis of the groups of working and non-working older people, a number of 
interconnections of different criteria can be traced, which determine the cause-effect relationship. In the group of working elderly people, the relationship between the criteria "subjective well-being" and "friendly family", "love and interpersonal relationships" is traced. In this group of respondents, the level of "subjective well-being" is the higher, the smaller the family of a working pensioner. In the group of unemployed elderly people there is a correlation between the criterion of "subjective well-being" and indicators: "goal of life", "life process", "life in pleasure", "communicative competence", "self-realization".

Based on the studies, it should be said that the correctional targets are different for working and non-working elderly people, but this population is suitable for participation in public life and can be involved in the creative process, taking into account their skills, personal aspirations [5,7]. Considering that the contribution of pensioners to the development of the economy, the social sphere, and the upbringing of the younger generation is many times higher than the state's material costs for the maintenance of older people, modern measures to ensure social groups (working and non-working pensioners) should be aimed at creating a decent and comfortable life for elderly Russians.

\section{References}

1. I.Yu. Antonova, A.A. Adzhinyazova, E.V. Ermolaeva, Bulletin of medical Internet conferences 5(12), 1517 (2015).

2. V. L. Bengtson, R. Settersten Jr (Eds.), Handbook of theories of aging. Springer Publishing Company (2016).

3. A. M. Ahmed, L. Andersson, M. Hammarstedt, Applied Economics Letters 19(4), 403406 (2012).

4. N. Y. Kirsanova, O. M. Lenkovets, Life Sci. J 11(6), 179-207 (2014).

5. I. Petkova, D. Vaycheva, Sci J Interactive Science, 203-213 (2016).

6. D. J. Mitchell, Pensions, Politics and the Elderly: Historic Social Movements and Their Lessons for Our Aging Society (Routledge, 2016).

7. M. R. Franco, A. Tong, K. Howard, et al., Br J Sports Med 49(19), 1268-1276 (2015). 